Article

\title{
Thermo-Hydraulic Analysis of a Tri-Axial High-Temperature Superconducting Power Cable with Respect to Installation Site Geography
}

\author{
Youngjun Choi ${ }^{1}$, Dongmin Kim ${ }^{1}$, Changhyung Lee ${ }^{1}$, Duyeon Won ${ }^{2}$, Jaeun Yoo ${ }^{2}$, \\ Hyungsuk Yang ${ }^{2}$ and Seokho Kim ${ }^{1, * \mathbb{D}}$ \\ 1 Department of Mechanical Engineering, Changwon National University, Changwon 641-773, Korea; \\ dydwns4739@gmail.com (Y.C.); iamdongmin@gmail.com (D.K.); chlee8612@gmail.com (C.L.) \\ 2 Korea Electric Power Corporation Research Institute, Daejeon 34056, Korea; won3412028@kepco.co.kr (D.W.); \\ jyoo@kepco.co.kr (J.Y.); h.yang@kepco.co.kr (H.Y.) \\ * Correspondence: seokho@changwon.ac.kr; Tel.: +82-55-213-3607
}

Received: 8 June 2020; Accepted: 30 July 2020; Published: 30 July 2020

\begin{abstract}
Various high-temperature superconducting (HTS) power cables are being developed or are ready for commercial operation to help energy suppliers meet the growing power demand in urban areas. Recently, triaxial HTS power cables have been developed by Korea Electric Power Corporation (KEPCO) and LS Cable \& System. Further, KEPCO has been planning to install a 2 $\mathrm{km}$ long $23 \mathrm{kV} / 60$ MVA triaxial HTS power cable to connect the Munsan and Seonyu substations and increase the stability of the power grid. The HTS power cables should be cooled down to a cryogenic temperature near $77 \mathrm{~K}$. A thermo-hydraulic analysis of the cooling system considering the geographical characteristics of the installation site is essential for long-distance sections. This paper describes the thermo-hydraulic analysis of the triaxial HTS power cable to determine the proper mass flow rates of subcooled liquid nitrogen that meet the operating temperature and pressure of the cable for four configurations of cooling systems: (1) a single cooling system with an external return path, (2) a dual cooling system with an external return path, (3) a single cooling system with an internal return path, and (4) a dual cooling system with internal return path. Since the flow characteristics in a corrugated cable cryostat differ significantly from those in a typical annular tube, a computational fluid dynamics (CFD) analysis was conducted to estimate the pressure drop along the cable cryostat. With the CFD analysis and given heat loads in the cable, the temperature and the pressure variations along the cable were calculated and their pros and cons were compared for each configuration of the cooling system. This thermo-hydraulic analysis will be referenced in the actual installation of the HTS power cable between the Munsan and Seonyu substations.
\end{abstract}

Keywords: high-temperature superconductor; HTS power cable; pressure drop; heat loss; thermo-hydraulic analysis

\section{Introduction}

High-temperature superconducting (HTS) power cables with low electric loss and large power capacities are being developed or are ready for commercial operation to meet the increasing energy demand in downtown areas [1-5]. Korea Electric power Corporation (KEPCO) and LS Cable \& System commercialized a $23 \mathrm{kV}, 50$ MVA superconducting cable in the Singal-Heungdeok section that is approximately $1 \mathrm{~km}$ long. The Jeju smart-grid demonstration center completed the testing of a $1 \mathrm{~km}$, $154 \mathrm{kV}, 600$ MVA three-phase superconducting cable [6]. 
Recently, they developed a triaxial HTS cable with enhanced current characteristics, compared to a 3-core-in-1 cryostat type [7], and are now preparing its commercialization connecting the Munsan and Seounyu substations to increase the stability of the power grid $[5,8]$.

The HTS power cable is cooled by the circulation of subcooled liquid nitrogen $\left(\mathrm{LN}_{2}\right)$ at approximately $77 \mathrm{~K}$ in order to remove various heat losses such as AC loss, heat penetration into the cable, and the heat load at terminations. Increasing the mass flow rate of $\mathrm{LN}_{2}$ can reduce the temperature difference between the cable inlet and outlet, reducing the maximum temperature of the cable, but doing so increases the pressure across the cable. That is, the required mass flow rate of $\mathrm{LN}_{2}$ is determined to satisfy the operating temperature while the operating pressure is within the allowable limit.

There have been studies on computational fluid dynamic (CFD) analysis to predict the pressure drop due to the flow of liquid nitrogen in the cross-sectional shape of various types of superconducting cables [9-11]. To install a long HTS power cable over several kilometers, it is very important to determine the operating conditions for the "dedicated" HTS power cable in consideration of the heat transfer characteristics of the cable along with the flow characteristics associated with the actual installation environment.

In order to determine appropriate mass flow rate of $\mathrm{LN}_{2}$, it is necessary to investigate the thermo-hydraulic characteristics of the cable cryostat, and the details of the installation environments, such as vertical elevation, the locations and the number of joint boxes and terminals, should also be considered. The Munsan and Seonyu substations are $2.064 \mathrm{~km}$ apart from each other; along the installation path there are two vertical sections up to $27 \mathrm{~m}$, four terminals, and four joint boxes.

This paper describes the thermo-hydraulic analysis of the $23 \mathrm{kV} / 60$ MVA tri-axial HTS power cable to determine proper mass flow rates of subcooled liquid nitrogen that meet the operating temperature and pressure of the cable with four configurations of a cooling system: (1) a single cooling system with an external return path, (2) a dual cooling system with an external return path, (3) a single cooling system with an internal return path, and (4) a dual cooling system with internal return path. Since the flow characteristics in a corrugated cable cryostat differ significantly from that of a typical annular tube, a computational fluid dynamics (CFD) analysis was performed to estimate the pressure drop along the cable cryostat [12-14]. With the CFD analysis and given heat loads in the cable, the temperature and the pressure variations along the cable were calculated and their pros and cons were compared for each configuration of a cooling system. In addition, an expanded 1-D thermo-hydraulic network analysis was conducted to consider a radial heat transfer in a cable core that has an internal return path.

\section{Structure of Tri-Axial HTS Power Cable}

Table 1 lists the major specifications of triaxial HTS power cable. Brass laminated coated conductors are used as HTS wires to transport the current and PPLP (Polypropylene Laminated paper) is used for electric insulation in cryogenic environment.

Table 1. Specification of the triaxial high-temperature superconducting (HTS) power cable.

\begin{tabular}{cccccc}
\hline Type & $\begin{array}{c}\text { Electric Power } \\
\text { Capacity }\end{array}$ & $\begin{array}{c}\text { Line-To-Line } \\
\text { Voltage }\end{array}$ & Current & HTS Wire & Insulation \\
\hline $\begin{array}{l}\text { Tri-axial HTS } \\
\text { power cable }\end{array}$ & $60 \mathrm{MVA}$ & $23 \mathrm{kV}$ & $1.5 \mathrm{kA}_{\mathrm{rms}}$ & $\begin{array}{c}\text { Brass laminated } \\
\text { coated conductor }\end{array}$ & PPLP \\
\hline
\end{tabular}

The cable cryostat for the triaxial HTS power cable has a spiral corrugation geometry that makes it easy to bend the cable during installation; the cable core sags down to the cryostat due to gravity, not concentric shape. As shown in Figure 1, two types of the cable structure for flow path were considered: (a) the external return path type, and (b) the internal return path type. For an external return path, $\mathrm{LN}_{2}$ flows outside the cable core and then returns to the cooling system through a separate external return tube. In this case, the flow area of the external return tube is large enough that the pressure drop in the 
return tube is very small; however, there is additional heat loss in the return tube as in Figure 1a. The cable core consists of three HTS layers for each phase to conduct current, a central copper former to support concentric shape, an insulation layer between each phase of the cable for dielectric strength, and copper shield layers to transport fault current. For an internal return path, $\mathrm{LN}_{2}$ flows inside of the cable core and returns back through the outside of the cable core without requiring a separate external return tube [10,15-17]. This prevents additional heat loss of the external return tube and cools the wider surface area of the core. However, the pressure drop tends to increase due to the reduced flow area as in Figure 1b. In lieu of the copper former, the inner flow tube can serve as a concentric support [18].
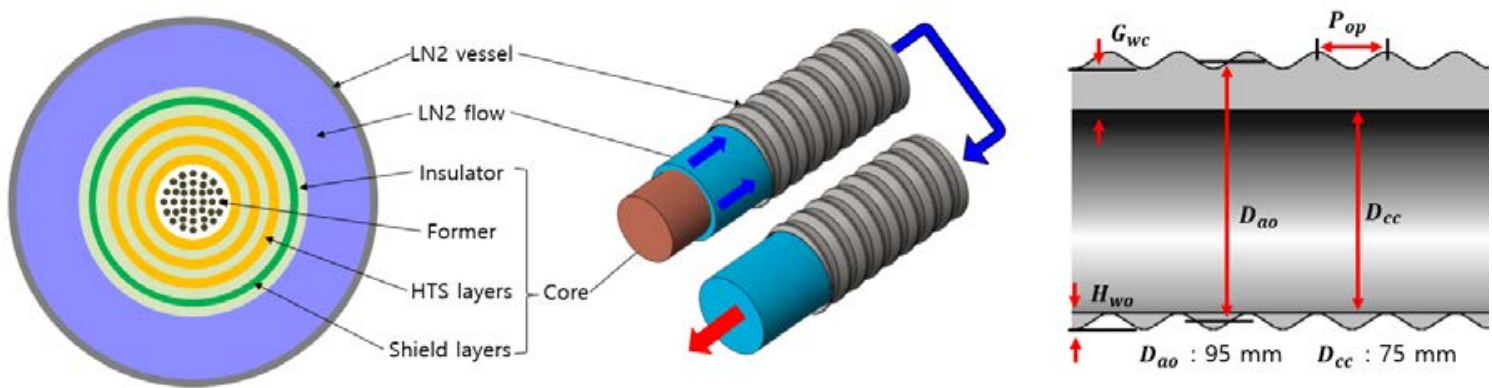

(a)
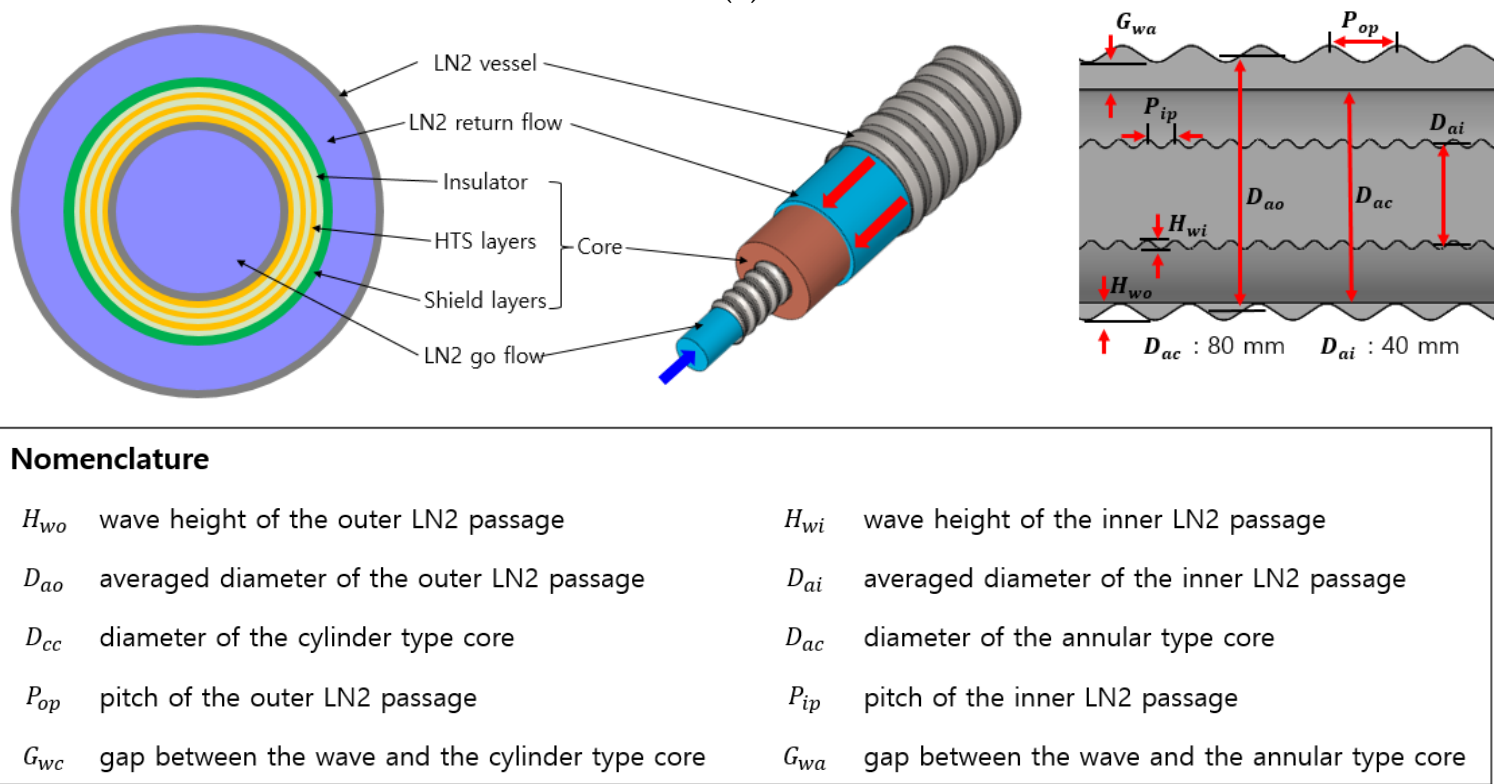

$H_{w i}$ wave height of the inner LN2 passage

$D_{a i} \quad$ averaged diameter of the inner LN2 passage

$D_{a c} \quad$ diameter of the annular type core

$P_{i p} \quad$ pitch of the inner LN2 passage

$G_{w a}$ gap between the wave and the annular type core

(b)

Figure 1. Structure of the triaxial HTS power cable with: (a) an external return path; (b) an internal return path.

\section{Geographical Characteristics of Installation Path}

The Munsan and Seonyu substations are $2.064 \mathrm{~km}$ apart from each other and there is also a platform between them. The platform functions as a switching station for terminal distribution lines instead of a convectional substation. The total distance from Munsan to the platform is $983 \mathrm{~m}$, with two terminals, two joint boxes, and a $25.5 \mathrm{~m}$ vertical section along the way. The distance from Seonyu to the platform is $1081 \mathrm{~m}$ long, with two terminals, two joint boxes, and a $27 \mathrm{~m}$ vertical section along the way. Figure 2 illustrates the layout of the triaxial HTS power cable between the Munsan and Seonyu substations.

$$
\Delta \mathrm{P}=\sum K_{b} \frac{\dot{m}^{2}}{2 \rho A^{2}}
$$




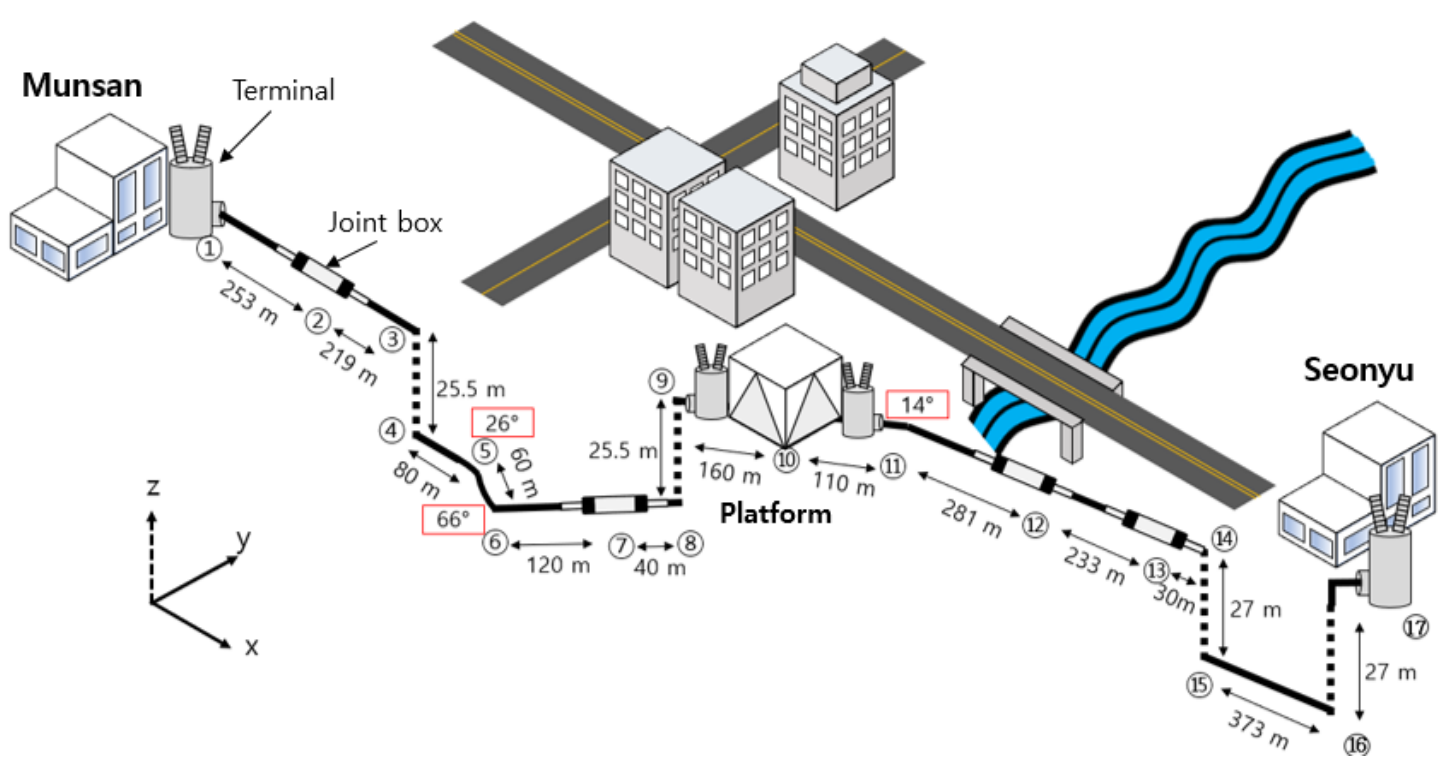

Figure 2. Layout of triaxial HTS power cable between Munsan and Seonyu substations.

Figure 3a shows the reference geometry for a cable snake and bending, which was applied for the $154 \mathrm{kV}, 600 \mathrm{MVA}$, 3-phase HTS power cable at the Jeju smart-grid demonstration center. Since a single-phase HTS power cable at the demonstration center has a similar shape to the triaxial HTS power cable, its installation characteristics such as bending and a cable snake were used as reference data. In the demonstration center, we observed a cable snake depth of $15 \mathrm{~cm}$ in the middle section of the HTS power cable for every $3.5 \mathrm{~m}$. The bending radius of the cable was 4.5 to $7 \mathrm{~m}$.

By modeling the cable snake as a sin wave as shown in Figure 3b, it was replaced with two 20.16-deg bending section with radius of $5 \mathrm{~m}$. Along the cable installation path of $2.064 \mathrm{~km}$, there are 1180 bends with a 20.16 bend angle. Figure 4 illustrates the minor loss coefficient for a bent round pipe. In this graph, the minor loss coefficient due to the bend becomes smaller as the ratio of the bending radius to the tube diameter increases; if this ratio is greater than 6 , the minor loss coefficient only depends on the bending angle. In the actual HTS power cable installation environment, the ratio of bending radius to the tube diameter is much larger than 6 . Since the HTS power cable will be installed along the existing underground installation tunnel, we considered eight 90 degree bending sections and one each of 26, 66 and 14 degree bending sections along the installation path referring to the layout of the underground cable installation site provided by KEPCO. Table 2 lists the calculation results of the minor loss coefficient on the cable snake and at the bend as obtained from Figure 4. The additional pressure drop due to the minor loss coefficient is calculated by Equation (1). The total additional pressure drop due to the minor losses from bending of the cable is $1439 \mathrm{~Pa}$ at $70 \mathrm{~K}, 7$ bar and $0.5 \mathrm{~kg} / \mathrm{s}$, and it seems to be negligible considering the estimated total pressure drop of the cable.

Table 2. Total minor loss coefficient of the HTS power cable between Munsan and Seonyu. substation.

\begin{tabular}{|c|c|c|}
\hline Angle of Bend $(\theta)$ & Number of Bends & Minor Loss $\left(K_{b}\right)$ \\
\hline $90^{\circ}$ & 8 & $0.131 \times 8$ \\
\hline $66^{\circ}$ & 1 & $0.114 \times 1$ \\
\hline $26^{\circ}$ & 1 & $0.067 \times 1$ \\
\hline $14^{\circ}$ & 1 & $0.043 \times 1$ \\
\hline $20.16^{\circ}$ & 1180 & $0.056 \times 1180$ \\
\hline \multicolumn{2}{|c|}{ Total minor loss coefficient } & 67.4 \\
\hline \multicolumn{2}{|c|}{ Pressure drop $(\mathrm{Pa}) @ 70 \mathrm{~K}, 7 \mathrm{bar}$ and $0.5 \mathrm{~kg} / \mathrm{s}$} & 1439 \\
\hline
\end{tabular}



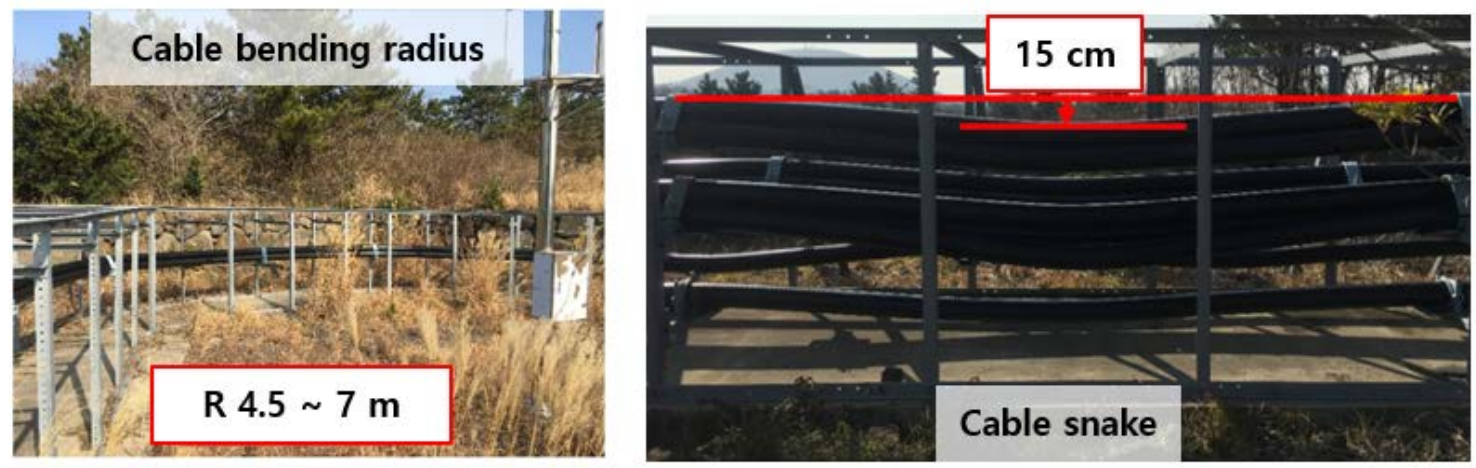

(a)

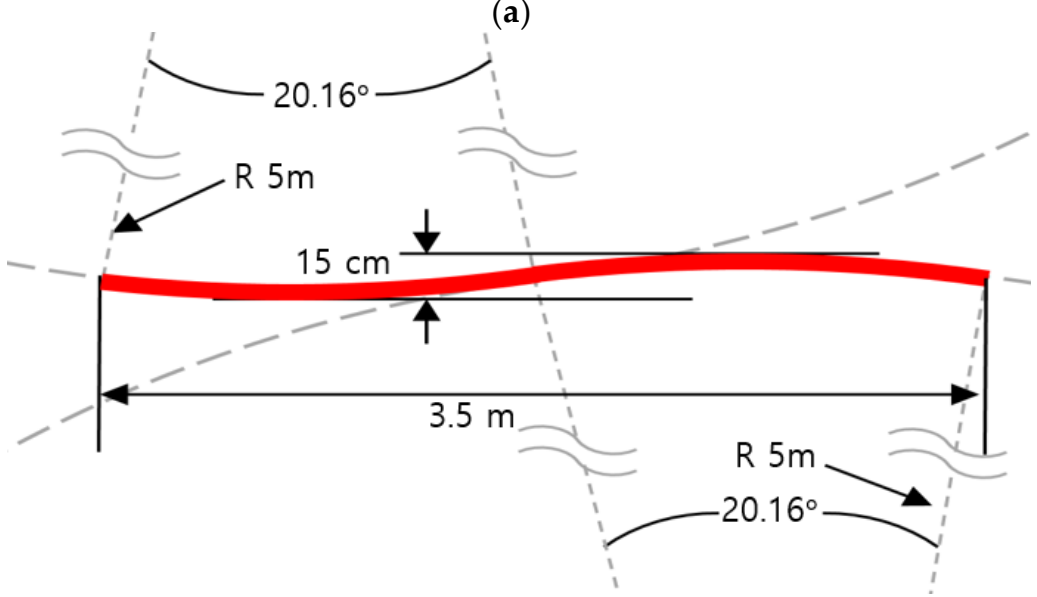

(b)

Figure 3. Installation environment in the Jeju smart-grid demonstration center: (a) Cable snake and cable bending radius; (b) cable snake assumed as bending.

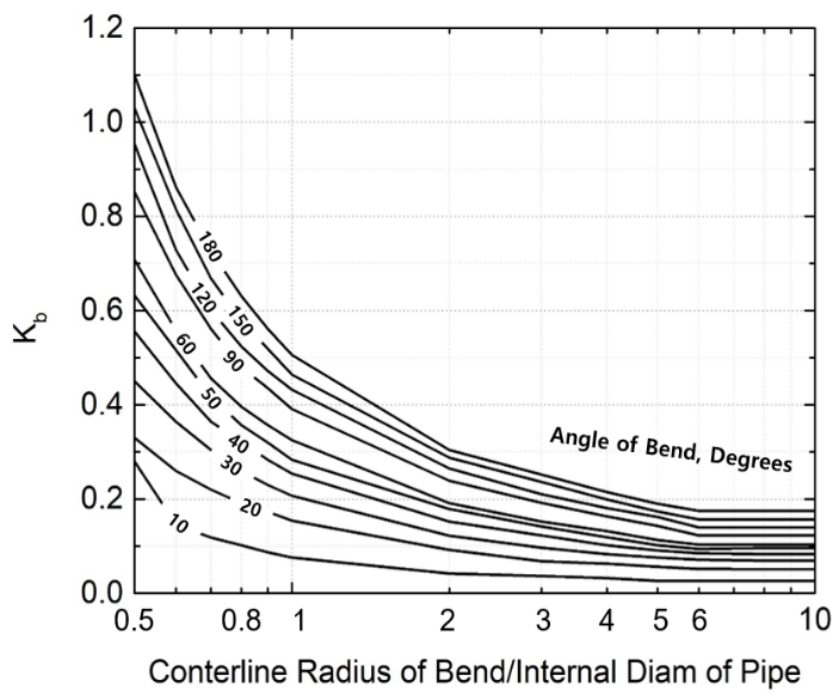

Figure 4. Minor loss coefficient for a bended round pipe (Babcock \& Wilcox Co., Barberton, OH, USA, 1978) [19].

\section{Single and Dual Cooling System with External Return Paths}

After circulating through the cable and the return tube, the temperature of $\mathrm{LN}_{2}$ increases and the pressure decreases due to heat loads and flow friction. Then, the $\mathrm{LN}_{2}$ is re-cooled using a cryogenic cooling system and pumped up to its original pressure using a cryogenic circulation pump [10]. Since 
the total length of cable is about $2 \mathrm{~km}$, two types of cryogenic cooling system were proposed considering the operating conditions and facility installation.

A cooling system can only be installed at the substations with sufficient installation space, and the options for the installation are described in Figure 5. Figure 5a,b show the configurations of cooling systems with an external return paths for a single cooling system at Munsan and dual cooling system, respectively. For the single cooling system, the initial installation cost is low; however, the estimated pressure drop is large, and each substation cannot be operated separately. If a fault occurred at one substation, both substations would have to be stopped for maintenance. In contrast, the dual cooling system incurs a high initial installation cost as it consists of two cooling systems; however, the pressure drop is relatively small, and it is easier to maintain because each substation can be operated separately.

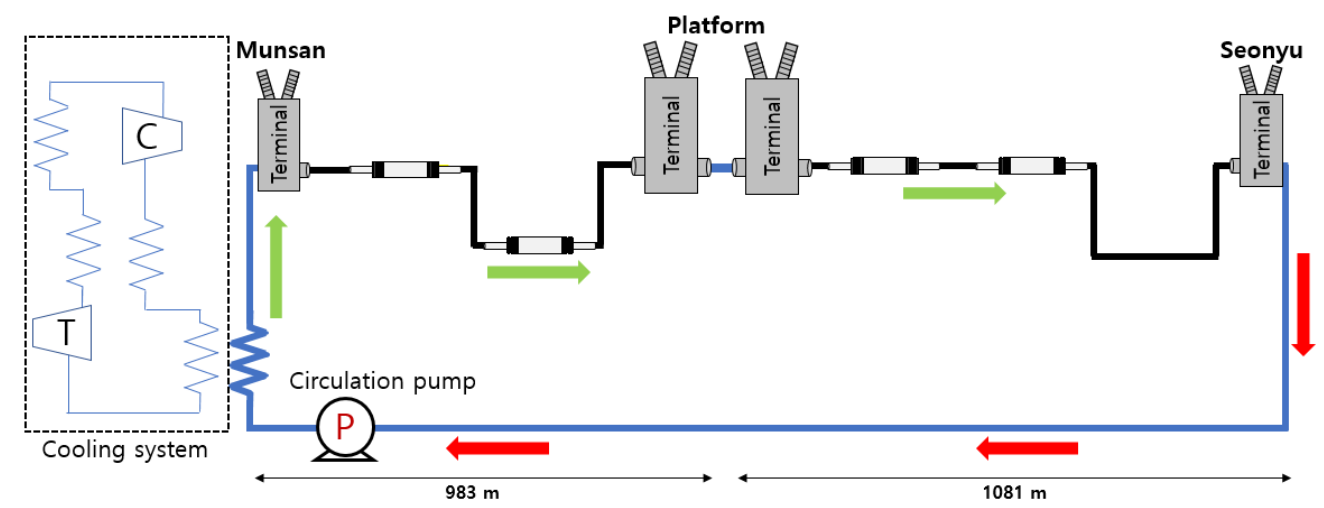

(a)

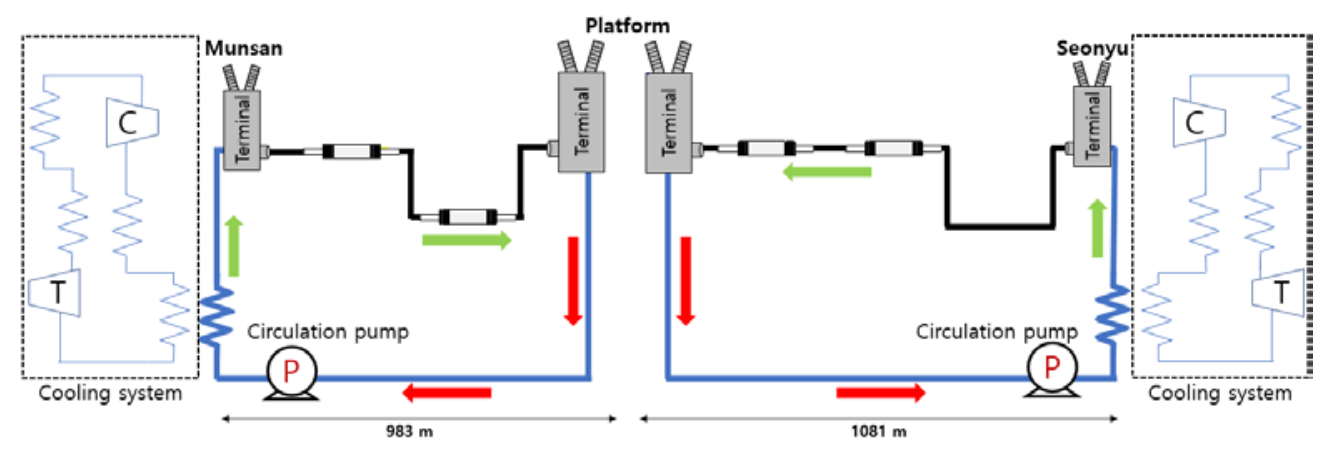

(b)

Figure 5. Configurations of cooling system with an external return path: (a) single cooling system at Munsan; (b) dual cooling system.

\section{Temperature Rise and Pressure Drop Analysis Model}

\subsection{Allowable Operating Conditions}

Considering the optimal electrical performance of HTS cables, the maximum temperature of the cooling system was set to $75.5 \mathrm{~K}$ and the minimum temperature to $67 \mathrm{~K}$ to prevent the freezing of $\mathrm{LN}_{2}$. The operating pressure of the cooling system was 13.5 bar at maximum due to the allowable pressure of the cable cryostat and 5.5 bar at minimum to suppress bubble generation. Therefore, the maximum temperature difference and the maximum pressure differential were $8.5 \mathrm{~K}$ and 8 bar, respectively, between the inlet and the outlet. Besides the pressure drop by flow friction, the pressure variations along the vertical section should be considered to ensure the maximum pressure is within the allowable pressure. Table 3 is the limiting operating conditions of the cooling system for the HTS power cable. 
Table 3. Allowable operating range of cooling system for triaxial HTS power cable.

\begin{tabular}{cccc}
\hline Parameter & Unit & Value & Comment \\
\hline Max. pressure limit & bar & 13.5 & Allowable pressure of cable cryostat \\
Min. Pressure limit & bar & 5.5 & Suppress the bubble \\
Max. temperature & $\mathrm{K}$ & 75.5 & Maximum temperature of HTS power cable \\
Min. temperature & $\mathrm{K}$ & 67.0 & Preventing freezing \\
\hline
\end{tabular}

\subsection{Calculation of $L N_{2}$ Temperature Variation}

Prior to detailed flow and thermal analysis using CFD, the temperature variation and the pressure drop can be estimated with simple equations assuming the 1-D simplification of the cable. Since the $\mathrm{LN}_{2}$ in the cryostat flows in the steady state, the temperature difference $(\Delta T)$ between the inlet and outlet is related to the energy balance equation of

$$
\Delta T=\frac{\dot{Q}}{\dot{m} C_{p}}
$$

where $\dot{m}$ and $C_{p}$ are the mass flow rate and the specific heat of $\mathrm{LN}_{2}$.

The total heat loss $\left(\dot{Q}_{\text {total }}\right)$ of the cooling system is calculated by

$$
\dot{Q}_{\text {total }}=\dot{Q}_{\text {cable }}+\dot{Q}_{\text {termination }}+\dot{Q}_{\text {jointbox }}+\dot{Q}_{\text {return }}
$$

where $\dot{Q}_{\text {cable }}$ is the estimated sum of heat losses at the cable including AC loss, dielectric loss and heat penetration into the cable cryostat, referring to the value provided by LS Cable, the cable manufacturer and the values of previous study based on FEM analysis [7]. $\dot{Q}_{\text {termination }}, \dot{Q}_{\text {jointbox }}$ and $\dot{Q}_{\text {return }}$ are the heat loss at terminations, joint boxes and heat penetration into the return tube, respectively. Referring to the previous analysis and experimental value, Table 4 lists the estimated heat losses of the triaxial HTS power cable [7].

Table 4. Heat loss of the triaxial HTS power cable with external return tube.

\begin{tabular}{ccccccc}
\hline & \multicolumn{3}{c}{ Munsan to Platform } & \multicolumn{3}{c}{ Seonyu to Platform } \\
\hline Parameter & $\begin{array}{c}\text { Length, } \\
\text { set }\end{array}$ & $\begin{array}{c}\text { Heat loss } \\
\text { per unit }\end{array}$ & $\begin{array}{c}\text { Total Heat } \\
\text { loss }\end{array}$ & $\begin{array}{c}\text { Length, } \\
\text { set }\end{array}$ & $\begin{array}{c}\text { Heat loss } \\
\text { per unit }\end{array}$ & $\begin{array}{c}\text { Total Heat } \\
\text { loss }\end{array}$ \\
\hline $\begin{array}{c}\text { HTS power cable }\left(\dot{Q}_{\text {cable }}\right) \\
\text { External return tube } \\
\left(\dot{Q}_{\text {return }}\right)\end{array}$ & $983 \mathrm{~m}$ & $3.5 \mathrm{~W} / \mathrm{m}$ & $3441 \mathrm{~W}$ & $1081 \mathrm{~m}$ & $3.5 \mathrm{~W} / \mathrm{m}$ & $3784 \mathrm{~W}$ \\
$\begin{array}{c}\text { Terminal } \\
\left(\dot{Q}_{\text {termination }}\right)\end{array}$ & $983 \mathrm{~m}$ & $1.0 \mathrm{~W} / \mathrm{m}$ & $983 \mathrm{~W}$ & $1081 \mathrm{~m}$ & $1.0 \mathrm{~W} / \mathrm{m}$ & $1081 \mathrm{~W}$ \\
$\begin{array}{c}\text { Joint box } \\
\left(\dot{Q}_{\text {jointbox }}\right)\end{array}$ & 2 set & $550 \mathrm{~W} / \mathrm{EA}$ & $1100 \mathrm{~W}$ & 2 set & $550 \mathrm{~W} / \mathrm{EA}$ & $1100 \mathrm{~W}$ \\
\hline & 2 set & $80 \mathrm{~W} / \mathrm{EA}$ & $160 \mathrm{~W}$ & 2 set & $80 \mathrm{~W} / \mathrm{EA}$ & $160 \mathrm{~W}$ \\
\hline & Sum & $5.68 \mathrm{~kW}$ & & Sum & & $6.13 \mathrm{~kW}$ \\
\hline
\end{tabular}

\subsection{Pressure Drop Model for the Cable Cryostat}

With a given pressure loss coefficient, the pressure drop $(\Delta \mathrm{P})$ in pipes is calculated by

$$
\Delta \mathrm{P}=f \frac{L}{D_{h}} \frac{\dot{m}^{2}}{2 \rho A^{2}}
$$

where $f, D_{h}, \rho, A$ are the pressure loss coefficient, the hydraulic diameter of HTS cable and return path, the density of $\mathrm{LN}_{2}$ and the flow area, respectively. Since the cable cryostats have a corrugation shape, the averaged diameter $\left(D_{a 0}\right)$ was used to calculate $D_{h}$ as in Figure 1. 
The moody chart generally shows friction coefficient $(f)$ from 0.008 to 0.1 . However, the $f$ is expected to be greater than 0.1 due to the shape of spiral corrugation. Then, the Colebrook-White equation of Equation (5) can be used to estimate the $f$ with the given relative roughness.

$$
\frac{1}{\sqrt{f}}=-2 \log \left(\frac{\varepsilon / D_{h}}{3.7}+\frac{2.51}{R e_{d} \sqrt{f}}\right)\left(R e_{d}>4000\right),
$$

where $\varepsilon, \varepsilon / D_{h}$ and $R e_{d}$ are the surface roughness, the relative roughness and the Reynolds number. Table 5 is representative value of flow parameters for each case.

Table 5. Representative value of flow parameters for each case.

\begin{tabular}{ccccc}
\hline \multirow{2}{*}{ Return Type } & Flow Path & $\mathbf{D}_{\mathbf{h}}(\mathbf{m m})$ & $\begin{array}{c}\text { Mass Flow } \\
\text { Rate } \mathbf{0 . 1} \mathbf{~ k g} / \mathbf{s}\end{array}$ & $\begin{array}{c}\text { Mass Flow } \\
\text { Rate 1 kg/s }\end{array}$ \\
\cline { 4 - 5 } & & & 4396 & 43,961 \\
\multirow{2}{*}{ External } & Inflow (annular) & 20.2 & 7836 & 78,369 \\
\hline \multirow{2}{*}{ Internal } & Return flow & 93.1 & 19,943 & 199,435 \\
& Inflow & 33.6 & 4280 & 42,801 \\
\hline
\end{tabular}

The wave height in a spiral corrugation can be simply assumed as a continuous surface roughness [20]. However, the flow stream is greatly affected by the large spiral pitch of the corrugation and the eccentric sagging of the cable core; further, it is necessary to define an equivalent relative roughness through CFD analysis to use Equations (4) and (5) for the pressure drop.

According to Equations (2) and (4), as the mass flow rate increases, the temperature difference decreases, and the pressure drop increases between the inlet and outlet of the HTS power cable.

\subsection{CFD Analysis of Spiral Corrugation Cryostat}

The mass flow rate was selected to be in the range $0.28-0.95 \mathrm{~kg} / \mathrm{s}$, which is the expected operating range of the cooling system to meet the allowable temperature and pressure limits. The detail process for the determination of appropriate mass flow rates is described in the next section. In the CFD analysis, the roughness of the cable cryostat and the cable core was assumed as smooth wall and $1 \mathrm{~mm}$ rough wall, respectively. The mass flow rate was selected to be in the range $0.28-0.95 \mathrm{~kg} / \mathrm{s}$, which is the expected operating range of the cooling system. The commonly used $k-\varepsilon$ turbulence model was applied using ANSYS CFX ver. 19.2. The length of the model was set to $2 \mathrm{~m}$ to ignore the entrance region. Table 6 lists the boundary conditions for the CFD analysis.

Table 6. CFD analysis boundary condition.

\begin{tabular}{cc}
\hline Parameter & Condition \\
\hline Working fluid & Subcooled liquid nitrogen \\
Mass flow rate & $0.28-0.95 \mathrm{~kg} / \mathrm{s}$ \\
$\mathrm{LN}_{2}$ temperature & $70 \mathrm{~K}$ \\
Average outlet pressure & 5.5 bar, $\mathrm{g}$ (static gauge pressure) \\
Model length & $2 \mathrm{~m}$ \\
Wall roughness & Core-1 mm rough wall, \\
Wall condition & Cable cryostat-smooth wall \\
Turbulence model & No-slip condition \\
$\mathrm{K}-\varepsilon$
\end{tabular}

Figure 6 shows the streamline of $\mathrm{LN}_{2}$ at a mass flow rate of $0.57 \mathrm{~kg} / \mathrm{s}$; it was possible to observe major straight flow and rotating flow along the spiral corrugation in each case. 


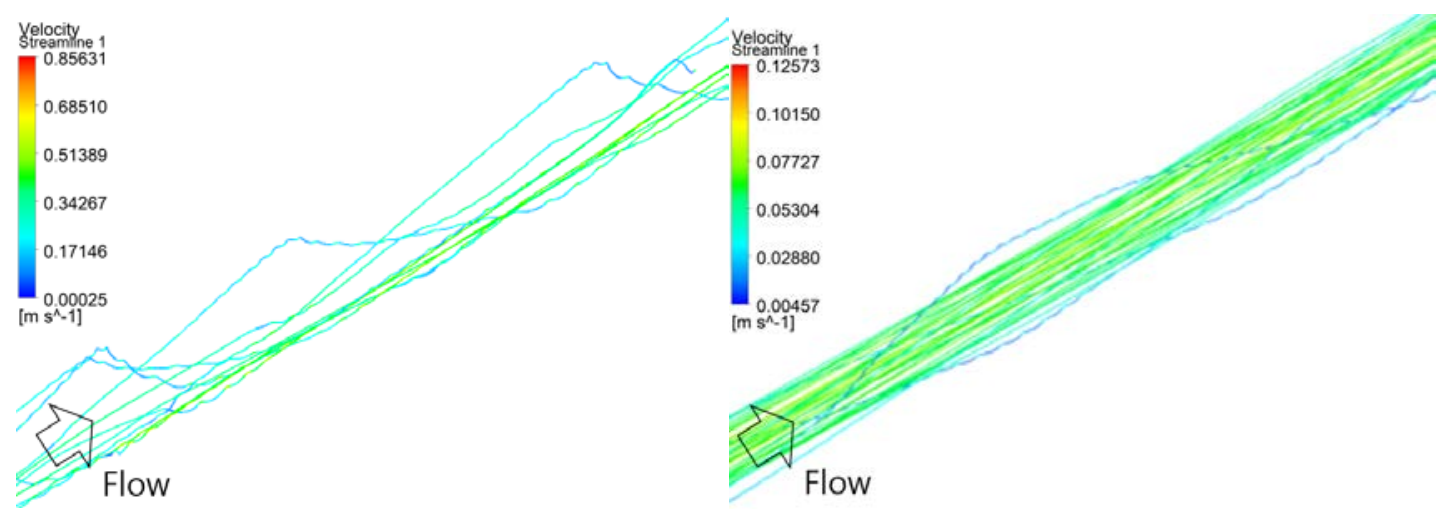

<Inflow, core outside>

$<$ External return $>$

(a) Cable with external return path
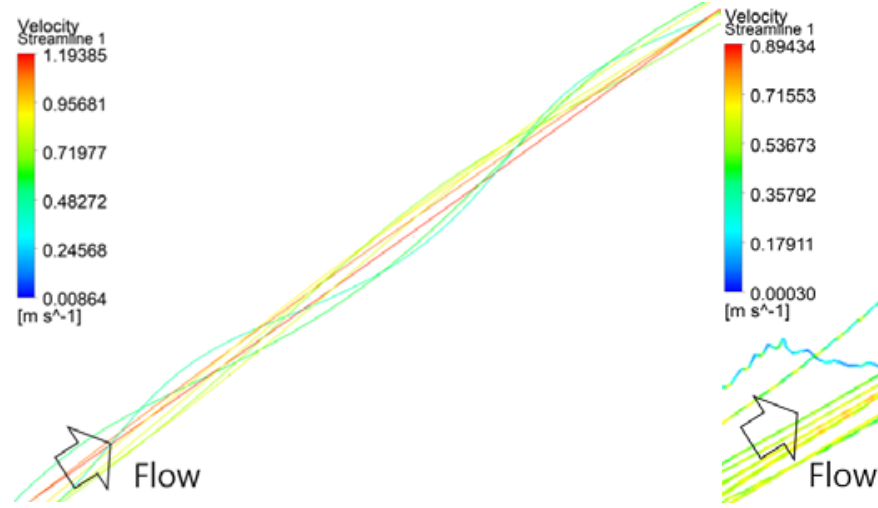

<Inflow, core inside>

<Internal return, core outside>

(b) Cable with internal return path

Figure 6. Streamlines in the computational fluid dynamic (CFD) analysis result for the: (a) cable with an external return path; (b) cable with internal return path at $0.57 \mathrm{~kg} / \mathrm{s}$.

Figure 7 is the pressure drop per unit length according to the mass flow rate in each flow path of the HTS power cable. The return flow of the internal return path had the greatest pressure drop per unit length. With the obtained pressure drop results, it is possible to determine the equivalent relative roughness for each flow path as in Table 7 by comparing the pressure drop with Equations (4) and (5). Then, the pressure drop can be simply calculated using Equations (4) and (5) instead of time consuming CFD analysis for the long HTS power cable. 


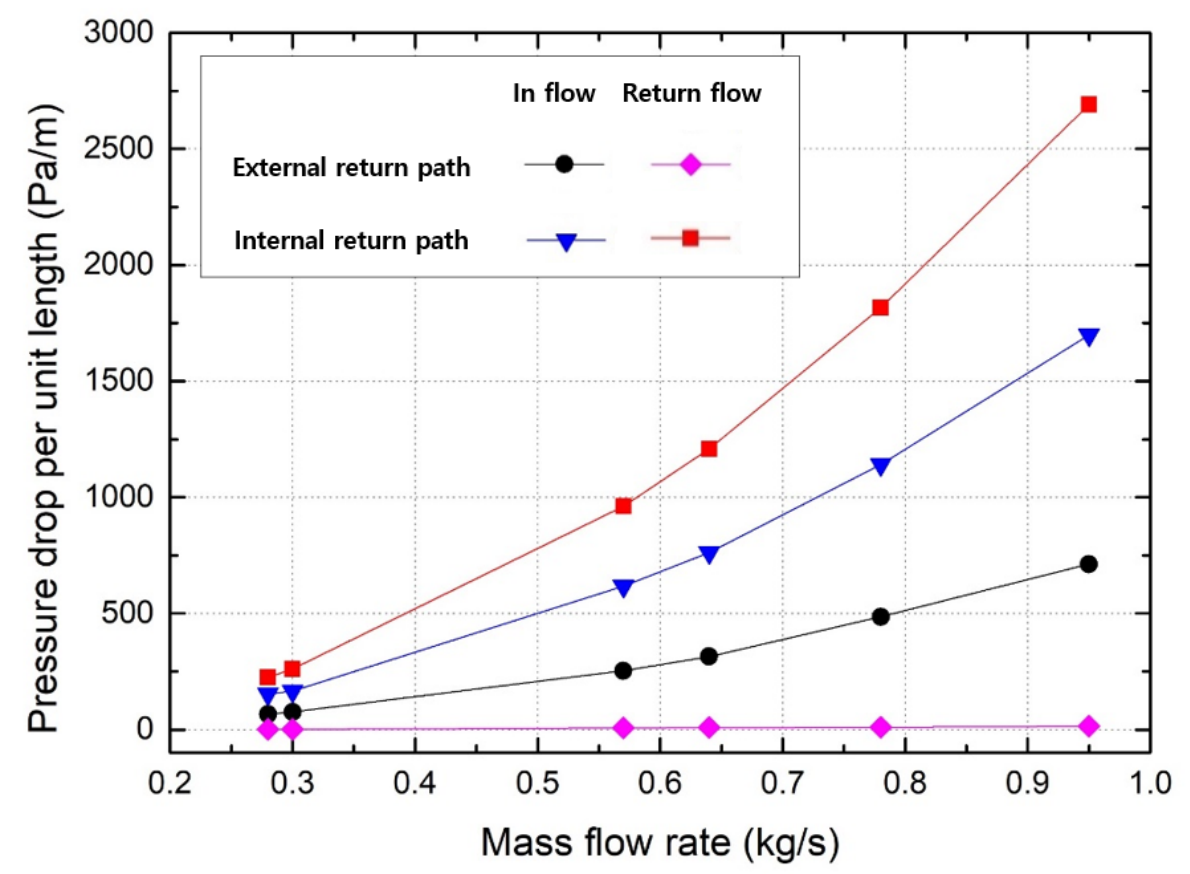

Figure 7. Pressure drop per unit length according to mass flow rate.

Table 7. Equivalent relative roughness of the HTS power cable CFD result.

\begin{tabular}{cccc}
\hline Return Type & Flow Path & $\begin{array}{c}\text { Relative Roughness of CFD } \\
(\mathbf{0 . 2 8}-\mathbf{0 . 9 5} \mathbf{~ k g} / \mathbf{s})\end{array}$ & $\begin{array}{c}\text { Equivalent Relative Roughness } \\
\left(\varepsilon / \boldsymbol{D}_{\boldsymbol{h}}\right) \text { for Equation (5) }\end{array}$ \\
\hline \multirow{2}{*}{ External } & Inflow & $0.238-0.269$ & 0.27 \\
& Return flow & $0.114-0.201$ & 0.21 \\
\hline \multirow{2}{*}{ Internal } & Inflow & $0.252-0.266$ & 0.27 \\
& Return flow & $0.303-0.320$ & 0.32 \\
\hline
\end{tabular}

\section{Pressure and Temperature Analysis Results for External Return Path}

The pressure drop for whole HTS power cable was calculated using Equation (4) with the equivalent relative roughness in Table 5. The temperature rise was calculated for the total heat loss in Figure 5 using Equation (2). Figure 8 shows the allowable mass flow rate of single cooling system and dual cooling systems with external return paths. For the single cooling system as in Figure 8a, the minimum mass flow rate was $0.57 \mathrm{~kg} / \mathrm{s}$ to meet the temperature limit and the maximum mass flow rate was $0.66 \mathrm{~kg} / \mathrm{s}$ to meet the pressure limit. In case of the dual cooling system on the Munsan side as in Figure $8 \mathbf{b}$, the minimum mass flow rate was $0.28 \mathrm{~kg} / \mathrm{s}$ to meet the temperature limit and the maximum mass flow rate was $0.98 \mathrm{~kg} / \mathrm{s}$ to meet the pressure limit. In case of the dual cooling system on the Seonyu side as in Figure 8c, the minimum mass flow rate was $0.3 \mathrm{~kg} / \mathrm{s}$ to meet the temperature limit and maximum mass flow rate was $0.93 \mathrm{~kg} / \mathrm{s}$ to meet the pressure limit. For the dual cooling system, the length of the path is shorter than for the single cooling system, resulting in a wide mass flow rate range. However, the pressure of $\mathrm{LN}_{2}$ increases depending on the laying of the actual cable in the underground vertical section [21]. According to Figure 2, there is a $27 \mathrm{~m}$ vertical section near the end of the terminal in the Seonyu substation and the pressure rise at this vertical section should be included in the calculated pressure drop in Figure 8. 


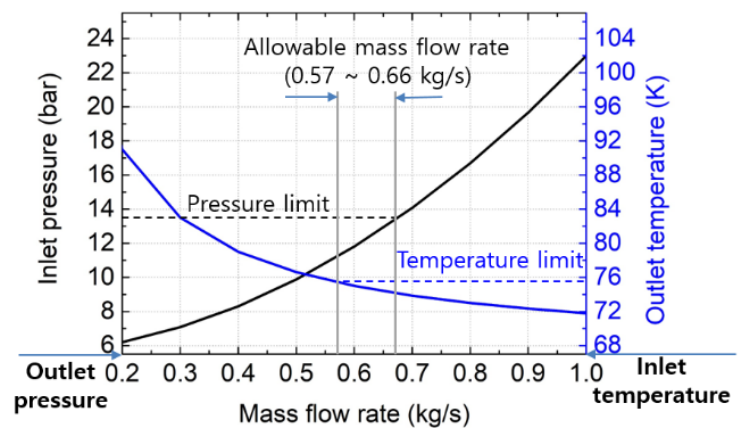

(a)

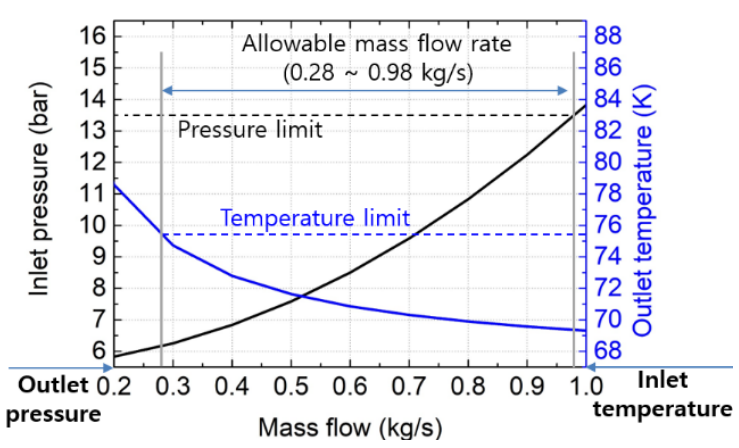

(b)

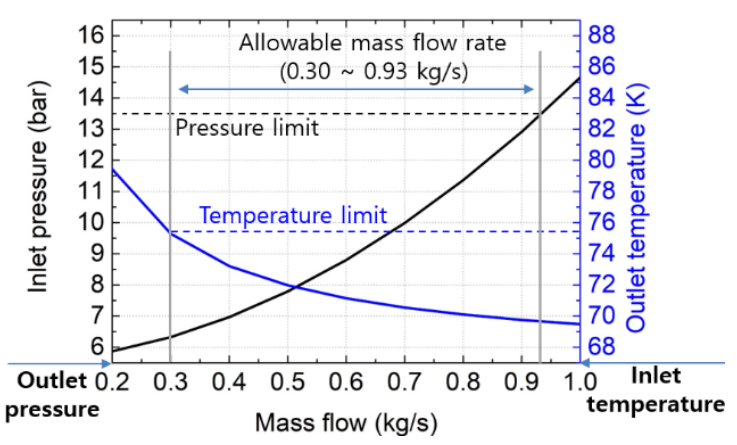

(c)

Figure 8. Allowable mas flow rates that meets the pressure limit and temperature limit for various cooling modes: (a) single cooling system; (b) dual cooling system, Munsan side; (c) dual cooling system, Seonyu side.

Figure 9 shows the pressure and temperature of each cooling system at the minimum mass flow rate along with the cable path. The pressure of the cable cryostat reaches its maximum in the vertical section. In particular, on the Seonyu side, the maximum pressure is approximately 2 bar greater than the outlet pressure, as the vertical section is closer to the inlet. The length of the path in the dual cooling system is shorter than that in the single cooling system; hence, the mass flow rate in the former is enough to satisfy the temperature limit.

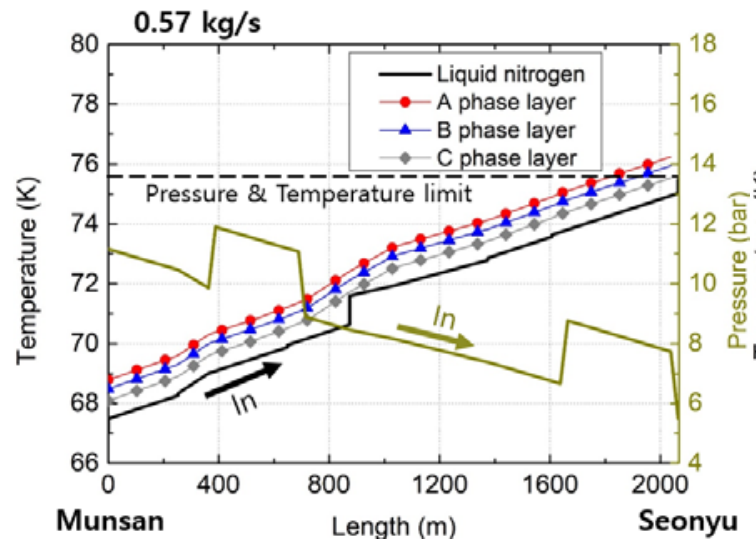

(a)

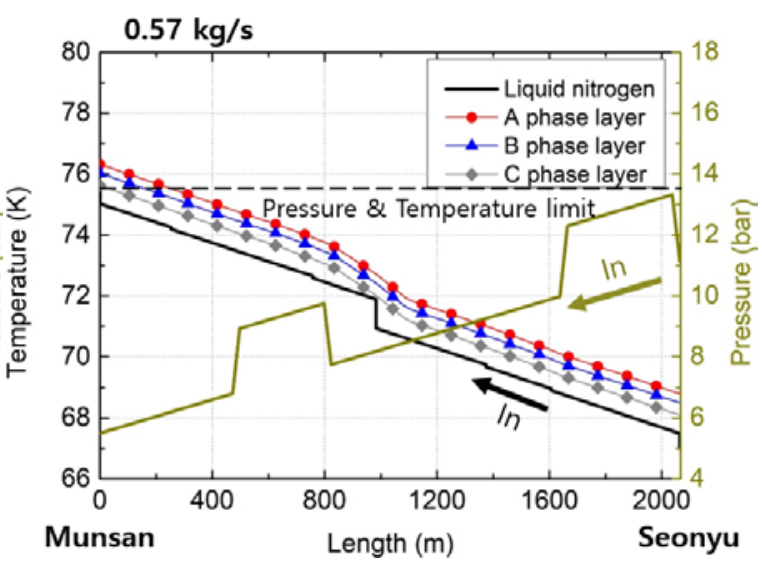

(b)

Figure 9. Cont. 


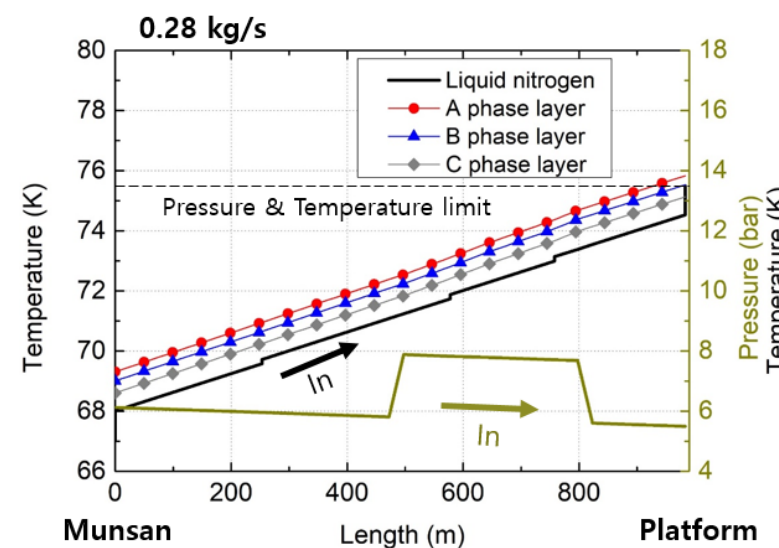

(c)

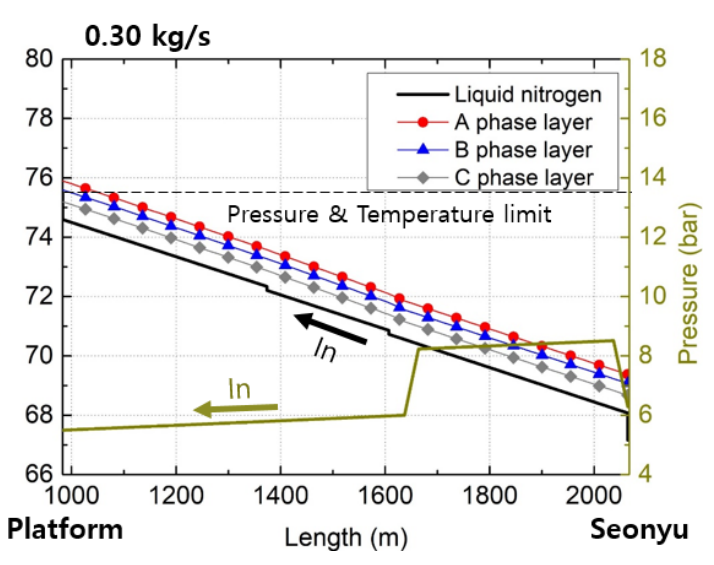

(d)

Figure 9. Temperature and pressure variations along the HTS power cable with an external return path: (a) single cooling system at Munsan; (b) single cooling system at Seonyu; (c) dual cooling system, Munsan side; (d) dual cooling system, Seonyu side. The mass flow rates are minimum values that meet the allowable temperature difference.

\section{Temperature and Pressure Analysis Results for Internal Return Path}

\subsection{Expanded One-Dimensional Thermo-Hydraulic Network Analysis Model}

For the internal return path, conduction heat transfer $\left(\dot{Q}_{\text {conduct }}\right)$ occurs in the core due to the temperature difference between the inflow and the return flow, as well as the electrical loss $\left(\dot{Q}_{\text {electrical }}\right)$ of the each conducting layer. Heat penetration $\left(\dot{Q}_{\text {thermal }}\right)$ is introduced into the LN2 through the cryostat. Convective heat transfer occurs continuously between the flow and the core. To analyze the internal return path cooling system, we conducted an expanded 1-D network analysis using a commercial software, SINDA/FLUINT [22,23]. The model consists of one node per $50 \mathrm{~m}$ cable, and the total number of nodes is approximately 400. Diffusion node means a solid having mass and heat capacity. Junction node means a fluid with temperature and pressure. The connection line between the diffusion nodes is conduction heat transfer and the connection line between the junction node and the diffusion node is convection heat transfer. For thermal conduction inside the cable core, equivalent thermal conductivity and heat capacity for the components in the cable were modeled. The convection by $\mathrm{LN}_{2}$ flow inside and outside of the cable core was considered in the analysis model.

The analysis was performed by referring to the pressure rise in the vertical section and the pressure drop per unit length in the CFD analysis results, and the model was simulated. Figure 10 illustrates the expanded 1-D network model and the heat balance of the internal return path.

Table 8 is thermal properties used in the expanded 1-D network model.

Table 8. Thermal properties of expanded 1-D network model.

\begin{tabular}{cccc}
\hline Diffusion Node Name & Material & $\begin{array}{c}\text { Thermal Conductivity } \\
(\mathbf{W} / \mathbf{m} \cdot \mathbf{K}) @ \mathbf{~} \mathbf{7 0 ~ K}\end{array}$ & Comments \\
\hline Conducting layer & - & 60.22 & Averaged value of HTS wire \\
Stabilizer & Copper & 512.96 & \\
Insulation & PPLP & 0.05 & Based on the measurement [24] \\
\hline
\end{tabular}




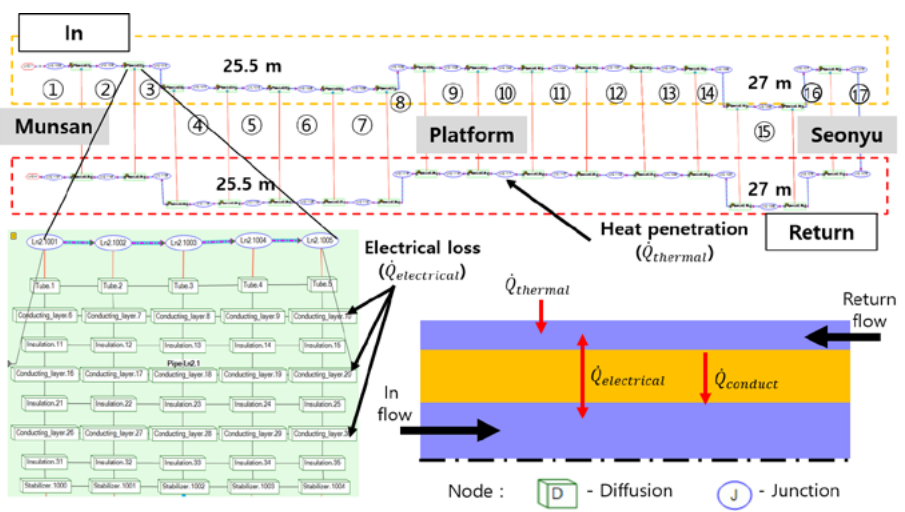

Figure 10. Expanded 1-D network model and heat balance diagram for the internal return path.

\subsection{Analysis Result for Internal Return Path}

Figure 11 is the result of the analysis at the maximum temperature condition for single and dual cooling systems. For the single cooling system as in Figure 11a,b, the minimum mass flow rate was $0.8 \mathrm{~kg} / \mathrm{s}$ to meet the temperature limit. However, due to the large pressure drop that occurs due the narrow flow area and the long path in the cable cryostat, it was not suitable for use. For the dual cooling system on the Munsan side as in Figure 11c, the minimum mass flow rate was $0.35 \mathrm{~kg} / \mathrm{s}$ to meet the temperature limit. On the Seonyu side as in Figure 11d, the minimum mass flow rate was $0.4 \mathrm{~kg} / \mathrm{s}$; however, it could not be applied because the pressure limiting condition was not satisfied. To implement the dual cooling system on the Seonyu side, it was necessary to increase the diameter of the cryostat and move the vertical section away from the inlet. The temperature in each phase of the triaxial HTS power cable was electrically stable as the cable was operated between the temperatures of the inflow and internal return flow.

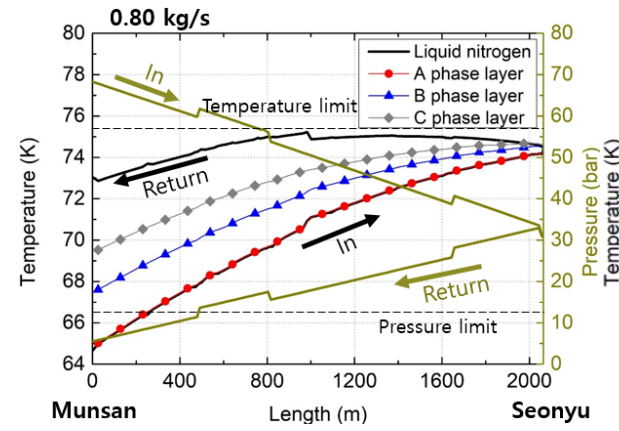

(a)

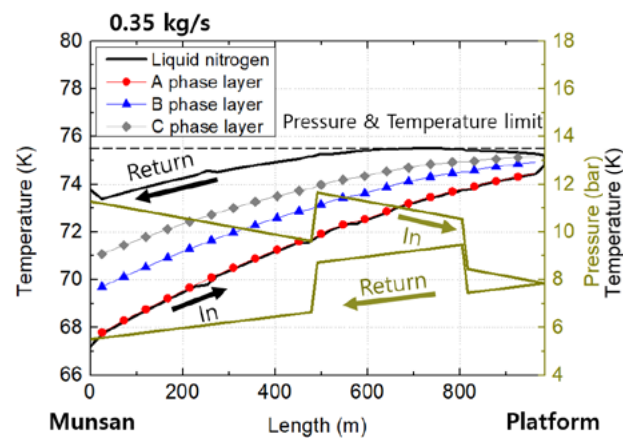

(c)

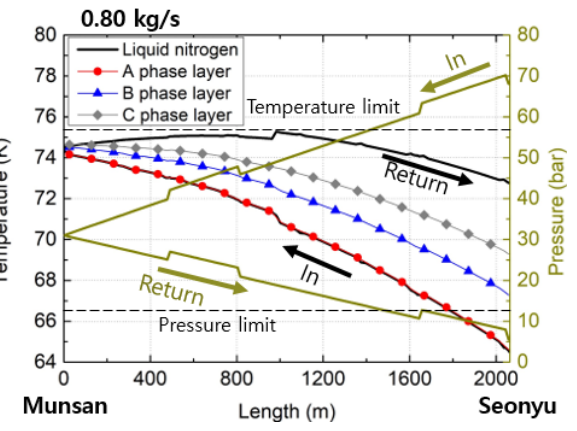

(b)

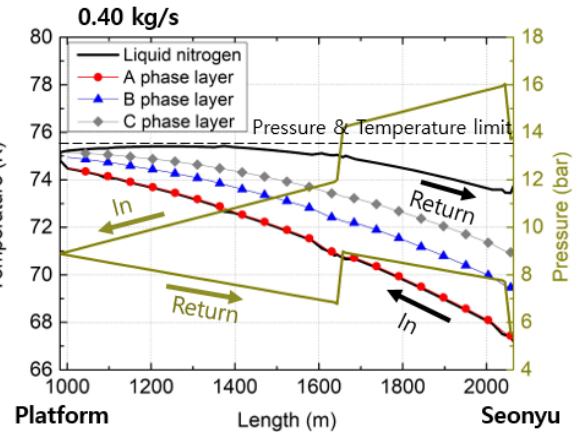

(d)

Figure 11. Temperature and pressure result at the position of internal return path: (a) single cooling system at Munsan; (b) single cooling system at Seonyu; (c) dual cooling system on the Munsan side; (d) dual cooling system on the Seonyu side. 


\section{Summary of Analysis Results Using Phase Diagram}

Temperature and pressure variations in Figures 9 and 11 are the result of analysis with minimum flow rates that meet the temperature differences. In addition, the possible maximum flow rates can be obtained by considering the pressure limit. The above two cases can be clearly demonstrated in a temperature-pressure phase diagram as in Figures 12 and 13, including pumping and cooling processes. Figure 12a,b are the phase diagrams for the single cooling system which is installed at Munsan and Seonyu with the external return path. The single cooling system at Munsan can operate from 0.57 to $0.66 \mathrm{~kg} / \mathrm{s}$. For the single cooling system at Seonyu, the pressure rise, due to the vertical section, occurred near the inlet; thus, the possible operating mass flow rate was reduced to 0.57 to $0.58 \mathrm{~kg} / \mathrm{s}$. With the dual cooling system, the allowable mass flow rate was 0.28 to $0.98 \mathrm{~kg} / \mathrm{s}$ for section between the Munsan station to the platform and 0.3 to $0.8 \mathrm{~kg} / \mathrm{s}$ for the section from the Seonyu station to the platform as in Figure 12c,d.

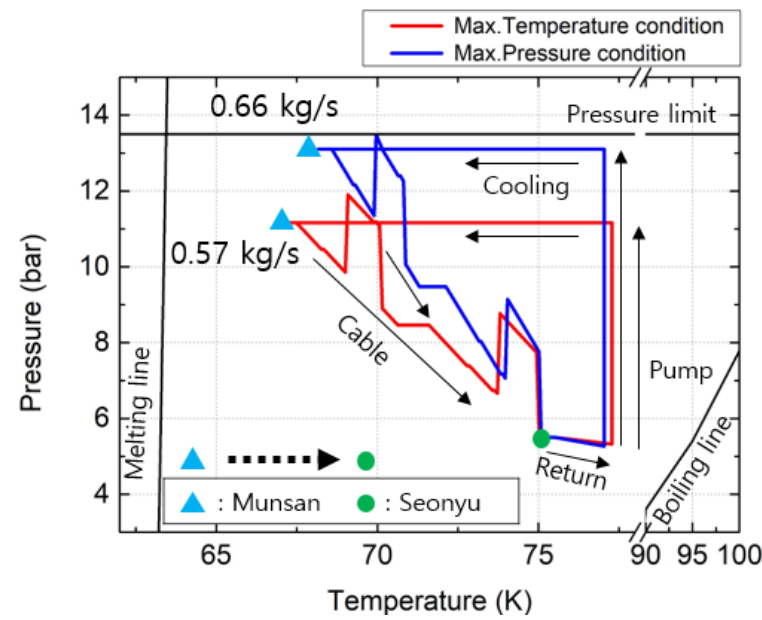

(a)

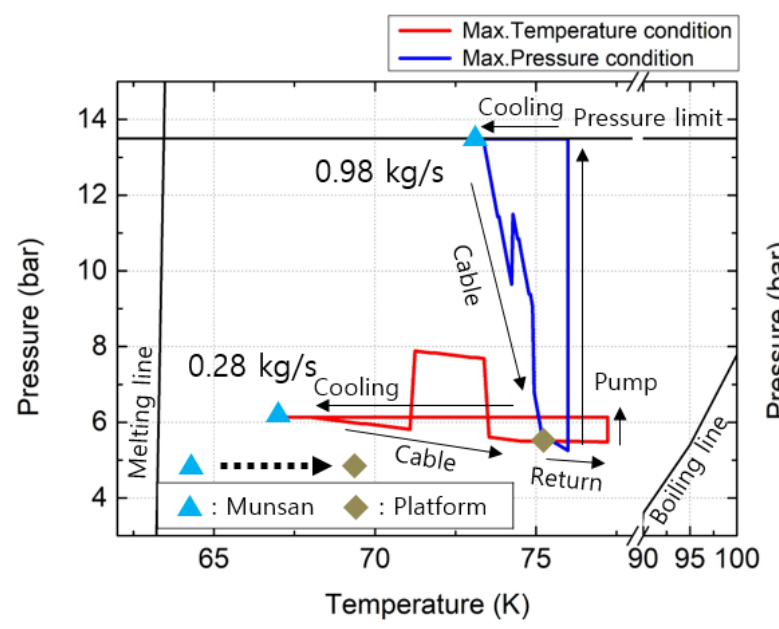

(c)

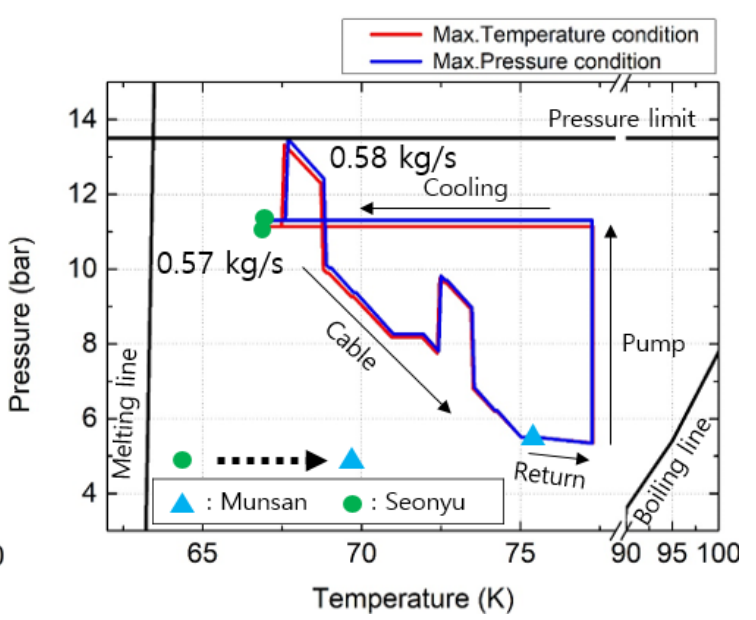

(b)

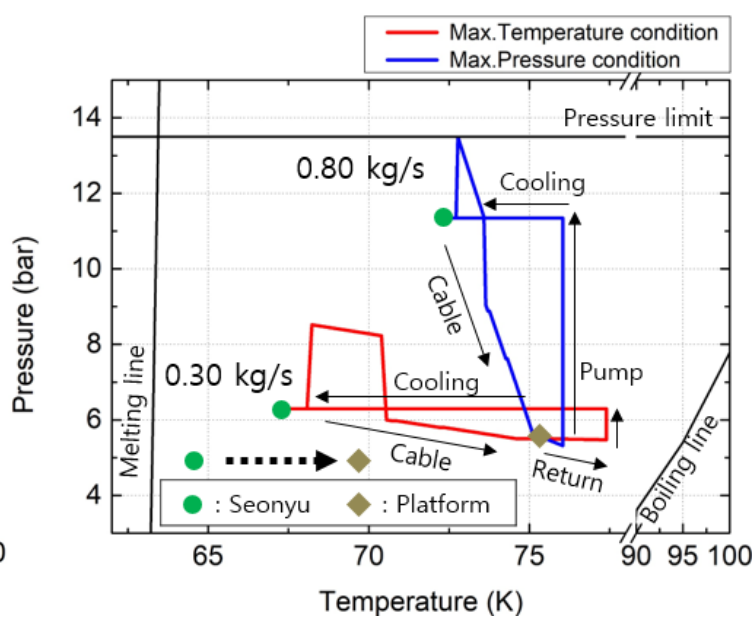

(d)

Figure 12. Possible operating range between pressure and temperature limit with external return path in phase diagram: (a) single cooling system at Munsan; (b) single cooling system at Seonyu; (c) dual cooling system, Munsan side; (d) dual cooling system, Seonyu side. 


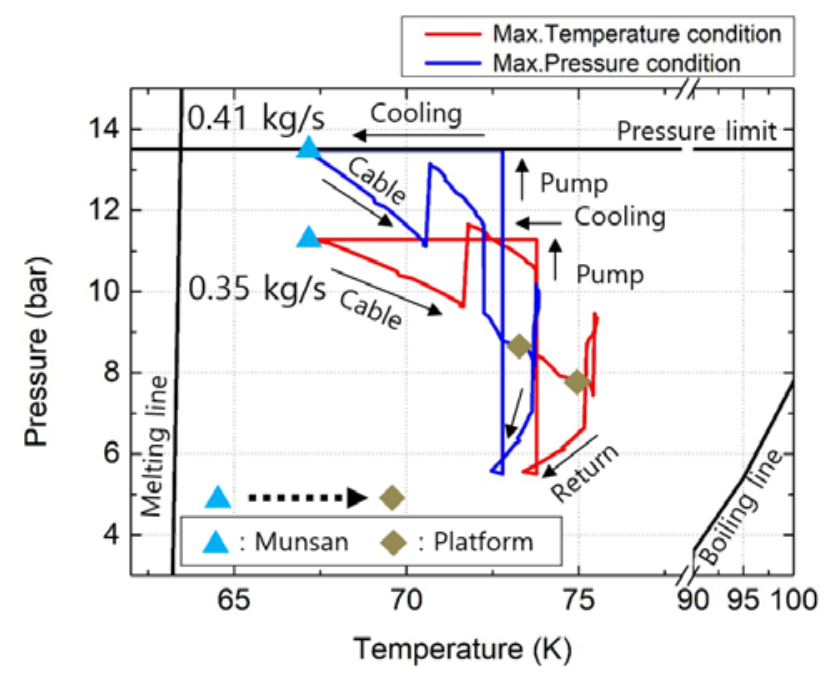

Figure 13. Possible operating range between pressure and temperature limit with internal return path in phase diagram, Munsan to platform.

For an internal return path with a single cooling system, it was impossible to meet the pressure limit due to the reduced flow area. With the dual cooling system, it was possible to obtain the allowable mass flow rate, 0.35 to $0.41 \mathrm{~kg} / \mathrm{s}$ from Munsan to the platform, while the pressure limit also exceeded the limit from Seonyu to the platform.

\section{Summary and Conclusions}

In this study, we conducted a thermo-hydraulic analysis of the single and dual cooling systems applicable to the external and internal return paths with the detailed geographical characteristics of the real installation environment. Through CFD analysis for the cable cryostat with spiral corrugations, it was possible to obtain the equivalent relative roughness to be used in 1-D hydraulic analysis for pressure drop. For a cable cooling system with an internal return path, we performed an expanded 1-D network analysis to consider the radial heat transfer within the cable core due to the temperature difference between the inflow and the return flow.

Table 9 summarizes the resultant allowable mass flow rates for each cooling mode. For the external return path of the single cooling system and the dual cooling system, we provided an adequate mass flow rate range. However, the internal return path cannot be operated in the single cooling system and dual cooling system for the Seonyu to platform section in spite of the low heat loss feature of the internal return path. To operate the cooling system with an internal return path, the flow area should be increased, and the vertical section should be moved away from the inlet, or a cable cryostat with a high allowable pressure should be used. We believe that the thermo-hydraulic analysis model and results will be used as a design and operation guide for a cryogenic cooling system for the future installation of the triaxial HTS power cable between the Munsan and Seonyu substations.

In this paper, we did not consider the fault situation. Prior to installing the triaxial HTS power cable, additional components in previously demonstrated HTS power cable systems, such as a decompressing cooling chamber and a parallel circulation pump, will be considered against the fault condition. 
Table 9. Allowable mass flow rates for various cooling modes.

\begin{tabular}{cccc}
\hline Return Path & Cooling Mode & Section & Possible Mass Flow Rate (kg/s) \\
\hline \multirow{4}{*}{ External } & Single cooling at Munsan & Munsan to Seonyu & $0.57-0.66$ \\
& Single cooling at Seonyu & Seonyu to Munsan & $0.57-0.58$ \\
& Dual cooling & Munsan to platform & $0.28-0.98$ \\
& & Seonyu to platform & $0.30-0.80$ \\
\hline \multirow{4}{*}{ Internal } & Single cooling at Munsan & Musan to Seonyu & exceed pressure limit \\
& Single cooling at Seonyu & Seonyu to Munsan & exceed pressure limit \\
& Dual cooling & Munsan to platform & $0.35-0.41$ \\
& & Seonyu to platform & exceed pressure limit \\
\hline
\end{tabular}

Author Contributions: Y.C. prepared the investigation and performed CFD and the expanded 1-D thermo-hydraulic analysis; C.L. developed CFD analysis model; D.K. developed the expanded 1-D thermo-hydraulic network model; S.K. provided a supervisory role and managed the research; D.W., J.Y. and H.Y., funding acquisition. All authors have read and agreed to the published version of the manuscript.

Funding: This work was funded by Korea Electric Power Corporation.

Conflicts of Interest: The authors declare no conflict of interest.

\section{References}

1. Chikumoto, N.; Watanabe, H.; Yury, V.I.; Takano, H.; Yamaguchi, S.; Koshizuka, H.; Hayashi, K.; Sawamura, T. Construction and the circulation test of the 500-m and 1000-m DC superconducting power cables in Ishikari. IEEE Trans. Appl. Supercond. 2016, 26, 1-4. [CrossRef]

2. James, F.M.; Schmidt, F.; Bratt, S.; Tom, E.W.; Jie, Y. Installation and testing results of long island. IEEE Trans. Appl. Supercond. 2009, 19, 1692-1697.

3. Yang, H.S.; Kim, D.L.; Sohn, S.H.; Lim, J.H.; Choi, H.O.; Choi, Y.S.; Lee, B.S.; Jung, W.M.; Ryoo, H.S.; Hwang, S.D. Long term performance test of KEPCO HTS power cable. IEEE Trans. Appl. Supercond. 2009, 19, 1782-1784. [CrossRef]

4. Demko, J.A.; Sauers, I.; James, D.R.; Gouge, M.J.; Lindsay, D.; Roden, M.; Tolbert, J.; Willén, D.; Træholt, C.; Nielsen, C.T. Three-phase HTS cable for the AEP bixby project. IEEE Trans. Appl. Supercond. 2007, 17, 2047-2050. [CrossRef]

5. Lee, S.; Kang, S.Y.; Park, M.; Won, D.; Yoo, J.; Yang, H.S. Performance analysis of real-scale 23 kV/60 MVA class tri-axial HTS power cable for real-grid application in Korea. Energies 2020, 13, 2053. [CrossRef]

6. Jeong, K.W.; Moon, B.S.; Park, S.K. Status and Future Direction of HTS Power Application in KEPCO. Available online: http://www.csee.org.cn/data/zt_cigreAorc/doc/PL-18.pdf (accessed on 30 June 2020).

7. Lee, C.; Kim, D.; Kim, S.; Won, D.Y.; Yang, H.S. Thermo-hydraulic analysis on long three-phase HTS power cable of several kilometers. IEEE Trans. Appl. Supercond. 2019, 29, 5402805. [CrossRef]

8. Takeshi, F.; Jun, N.; Mitsugi, O.; Takao, Y.; Osami, S.T. Analysis of AC loss and current distribution characteristics of multi-layer three-phase HTS cable for 3-phase AC power transmission. IEEE Trans. Appl. Supercond. 2006, 16, 135-138.

9. Sasaki, A.; Ivanov, Y.; Yamaguchi, S. LN2 circulation in cryopipes of superconducting power transmission line. Cryogenics 2011, 51, 471-476. [CrossRef]

10. Yeom, H.-K.; Koh, D.-Y.; Kim, S.-H.; Seo, T.-B. Design of cryogenic systems for $154 \mathrm{kV}$ HTS power cable. IEEE Trans. Appl. Supercond. 2010, 20, 1296-1299. [CrossRef]

11. He, J.; Tang, Y.; Wei, B.; Li, J.; Ren, L.; Shi, J.; Wu, K.; Li, X.; Xu, Y.; Wang, S. Thermal analysis of HTS power cable using 3-D FEM model. IEEE Trans. Appl. Supercond. 2013, 23, 5402404.

12. Thadela, S.; Rao, V.V.; Agarwal, R.; Dondapatib, R.S. Computational investigation on thermohydraulic characteristics of high temperature superconducting (HTS) power cables. Phys. Supercond. Appl. 2019, 559, 25-31. [CrossRef]

13. Zuo, Z.Q.; Jiang, W.B.; Yu, Z.G.; Huang, Y.H. Liquid nitrogen flow in helically corrugated pipes with insertion of high-temperature superconducting power transmission cables. Int. J. Heat Mass Transf. 2019, 140, 88-99. [CrossRef] 
14. Dong, Y.; Huixiong, L.; Tingkuan, C. Pressure drop, heat transfer and performance of single-phase turbulent flow in spirally corrugated tubes. Exp. Therm. Fluid Sci. 2001, 24, 131-138. [CrossRef]

15. Fuchino, S.; Furuse, M.; Higuchi, N. Longitudinal temperature distribution in superconducting power cables with counter-flow cooling. IEEE Trans. Appl. Supercond. 2002, 12, 1339-1342. [CrossRef]

16. Zajaczkowski, B.; Giesbers, A.J.M.; Holtrust, M.; Haenen, E.; den Heijer, R. Feasibility of inline cooling in long distance HTS power line. Cryogenics 2011, 51, 180-186. [CrossRef]

17. Miyagi, D.; Sakakibara, R.; Shinozaki, Y.; Tsuda, M.; Hamajima, T. Suitable cable structure of HTS three-phase cable cooled by counter flow cooling method for long-distance power transmission. IEEE Trans. Appl. Supercond. 2018, 28, 5400705. [CrossRef]

18. Lee, S.; Sung, H.; Park, M.; Won, D.; Yoo, J.; Yang, H.S. Analysis of the temperature characteristics of three-phase superconducting power cable according to a liquid nitrogen circulation method for real-grid application in Korea. Energies 2019, 12, 1740. [CrossRef]

19. Stultz, S.C.; Kitto, B. Steam its Generation and Use, 41st ed.; The Babcock \& Wilcox Company: Barberton, $\mathrm{OH}$, USA, 2005; pp. 3-14.

20. Marušic-Paloka, E.; Pažanin, I. Effects of boundary roughness and inertia on the fluid flow through a corrugated pipe and the formula for the Darcy-Weisbach friction coefficient. Int. J. Eng. Sci. 2020, 152, 103293. [CrossRef]

21. Chang, H.; Ryu, K.N.; Yang, H.S. Cryogenic design of liquid-nitrogen circulation system for long-length HTS cables with altitude variation. Cryogenics 2017, 83, 50-56. [CrossRef]

22. Heat Transfer and Fluid Analysis Software, SINDA/FLUINT. Available online: crtech.com/products/ sindafluint (accessed on 27 June 2020).

23. Sakowski, B.; Daniel, M.H.; Jason, W.H.; Kassemi, M. Validation of heat transfer correlations in line chill-down tests of cryogenic fluid in SINDA/FLUINT. In Proceedings of the 2018 International Energy Conversion Engineering Conference, Cincinnati, OH, USA, 9-11 July 2018.

24. Choi, Y.S.; Kim, D.L. Thermal property measurement of insulating material used in HTS power device. Cryogenics 2012, 52, 465-470. [CrossRef]

(C) 2020 by the authors. Licensee MDPI, Basel, Switzerland. This article is an open access article distributed under the terms and conditions of the Creative Commons Attribution (CC BY) license (http://creativecommons.org/licenses/by/4.0/). 